\title{
Aciotis, Acisanthera, Marcetia, Microlepis, Pterolepis e Siphanthera (Melastomataceae, Melastomeae) no Estado do Paraná, Brasil
}

\author{
Aciotis, Acisanthera, Marcetia, Microlepis, Pterolepis and Siphanthera (Melastomataceae)
}

in Paraná state, Brazil

\author{
Fabrício Schmitz Meyer ${ }^{1} \&$ Renato Goldenberg ${ }^{2,3}$
}

\begin{abstract}
Resumo
Os gêneros Aciotis D.Don, Acisanthera P. Browne, Marcetia DC., Microlepis (DC.) Miq., Pterolepis (DC.) Miq., Siphanthera Pohl ex DC., além de Tibouchina Aubl., são os representantes da tribo Melastomeae no estado do Paraná. À exceção do último, cada um apresenta apenas uma espécie no estado, respectivamente: Aciotis paludosa (Mart. ex DC.) Triana, Acisanthera variabilis (DC.) Triana, Marcetia taxifolia (A.St.-Hil.) DC., Microlepis oleifolia (DC.) Triana, Pterolepis glomerata (Rottb.) Miq. e Siphanthera cordata Pohl ex DC. Os registros de Microlepis e Siphanthera são os primeiros para estes gêneros no Paraná e região Sul. Neste trabalho foi elaborado um tratamento taxonômico para as espécies de Melastomeae no Estado, exceto para Tibouchina. São fornecidas chave de identificação, descrições dos gêneros e espécies, comentários taxonômicos, ilustrações, informações sobre distribuição geográfica e listagens de materiais examinados.

Palavras-chave: Melastomataceae, Melastomeae, taxonomia.
\end{abstract}

\begin{abstract}
The genera Aciotis D.Don, Acisanthera P. Browne, Marcetia DC., Microlepis (DC.) Miq., Pterolepis (DC.) Miq., Siphanthera Pohl ex DC., and Tibouchina Aubl. represent the tribe Melastomeae in the state of Paraná. Except for Tibouchina, each has only one species occurring in the state, respectively: Aciotis paludosa (Mart. ex DC.) Triana, Acisanthera variabilis (DC.) Triana, Marcetia taxifolia (A.St.-Hil.) DC., Microlepis oleifolia (DC.) Triana, Pterolepis glomerata (Rottb.) Miq. and Siphanthera cordata Pohl ex DC. Microlepis and Siphanthera are cited for the first time in Paraná and in southern Brazil. In this article we present a taxonomic treatment for the species of tribe Melastomeae in the state, except for those of Tibouchina, with an illustrated identification key, descriptions, information on distribution and taxonomy, and collectors' lists.
\end{abstract}

Key-words: Melastomataceae, Melastomeae, taxonomy.

\section{Introdução}

Melastomataceae é composta por cerca de 150-166 gêneros e 4.200-4.500 espécies distribuídas nas regiões tropicais do globo (Renner 1993; Clausing \& Renner 2001). A classificação supra genérica aceita para a família reconhece 9 tribos (Renner 1993) e, mais recentemente, uma nova tribo foi proposta (Penneys et al. 2010). Dentre estas, destaca-se Melastomeae, com cerca de 450 espécies, caracterizada pelos estames com conectivo apendiculado e sementes cocleadas (Renner 1993). No estado do Paraná a tribo está representada pelos gêneros Aciotis D.Don, Acisanthera P. Browne, Marcetia DC., Microlepis (DC.) Miq., Pterolepis (DC.) Miq., Siphanthera Pohl ex DC. e Tibouchina Aubl., reconhecidos pelos estames geralmente com conectivo ventralmente apendiculado (inapendiculado apenas em Aciotis) e frutos secos e deiscentes (Cogniaux 1883-1885, 1891).

Neste trabalho foi efetuado o estudo taxonômico dos gêneros pertencentes à tribo Melastomeae ocorrentes no estado do Paraná, à

\footnotetext{
${ }^{1}$ Universidade Estadual de Campinas, Depto. Biologia Vegetal, Programa de Pós-Graduação em Biologia Vegetal, Campus Universitário Zeferino Vaz, 13083970, Campinas, SP, Brasil

${ }^{2}$ Universidade Federal do Paraná, Centro Politécnico, Setor de Ciências Biológicas, Depto. Botânica, sala 447, C.P. 19031, 81531-970, Curitiba, PR, Brasil.

${ }^{3}$ Autor para correspondência: rgolden@ufpr.br
} 
exceção de Tibouchina, que é mais diverso e cuja publicação foi feita separadamente (Meyer et al. 2010). No presente estudo são fornecidas chave de identificação, descrições dos gêneros e espécies, comentários taxonômicos, informações sobre distribuição geográfica, listagens de materiais examinados e ilustrações.

\section{Materiais e Métodos}

As exsicatas analisadas estão depositadas nos herbários paranaenses FUEL, MBM e UPCB (siglas segundo Thiers, último acesso em 13.08.2011). No herbário HUEM não foram encontradas coletas dos táxons estudados. Para cada espécie, apenas as coletas provenientes do Estado do Paraná foram listadas como "material examinado", que serviram de base para as descrições. Quando necessário, por conta de escassez de coletas, foi também citado "material adicional examinado", proveniente de outros estados. Optou-se por citar apenas uma coleta por município, preferencialmente do registro mais recente, para encurtar a lista de material examinado.

Táxons infra-específicos não foram aceitos para o trabalho. Para a listagem de sinonímias e informações sobre distribuição geográfica foram realizadas consultas as obras de Baumgratz (2010), Cogniaux (1883-1885, 1891), Freire-Fierro (2002), Guimarães (2009), Kriebel (2010), Martins (1989,
2009), Martins \& Bernardo (2010), Matsumoto \& Martins (2009), Renner (1994), Romero (1997, 2000, 2009a,b, 2010a,b) e Wurdack (1962).

Com relação à morfologia, o número de nervuras laterais das folhas foi complementado com um sinal de adição acrescido do número dois quando constatada a ocorrência de um par submarginal tênue adicional (p.ex. $3+2$, com 1 nervura principal, 2 laterais e mais o par tênue).

Os dados fenológicos apresentados baseiamse apenas em coleções do Paraná.

Dados sobre a geografia, clima e vegetação do Paraná podem ser encontrados em Maack (1968) e Goldenberg (2004).

\section{Resultados}

Tratamento taxonômico

No estado do Paraná a tribo Melastomeae está representada pelos gêneros Aciotis, Acisanthera, Marcetia, Microlepis, Pterolepis, Siphanthera e Tibouchina. À exceção do último, estes gêneros são pouco diversos e sua ocorrência no Paraná geralmente representa seu limite setentrional de distribuição, como é o caso de Aciotis (FreireFierro 2002), Marcetia (Martins 1989), Microlepis e Siphanthera, ou quase, como é o caso de Acisanthera, Pterolepis e Tibouchina, que ocorrem até Santa Catarina e norte da Argentina (Wurdack 1962; Renner 1994).

\section{Chave de identificação para os gêneros e espécies da tribo Melastomeae ocorrentes no Paraná}

1. Ovário com ápice glabro.

2. Estames antepétalos ausentes; anteras com ápice rostrado (Fig. 3j) ............ Siphanthera cordata

2'. Estames antepétalos e ante-sépalos presentes; anteras com ápice subulado ou obtuso (Figs. 1e, j, 2e).

3. Conectivo inapendiculado (Fig. 1e) Aciotis paludosa

3'. Conectivo apendiculado, com apêndices muito ou pouco conspícuos (Figs. 1j, 2e).

4. Folhas planas, lâmina 1,2-3,3 × 1,2-2,3 cm (Fig. 1h); estames ante-sépalos com conectivo longamente prolongado, com 1,5-2,2 mm compr. (Fig. 1j) ...... Acisanthera variabilis

4'. Folhas assoveladas, lâmina $0,3-0,4 \times 0,1-0,2 \mathrm{~cm}$ (Fig. 2b); estames dos dois ciclos com conectivo curtamente prolongado, ca. $0,1 \mathrm{~mm}$ compr. (Fig. 2e) ...... Marcetia taxifolia

1'. Ovário com ápice coroado por indumento.

5. Hipanto externamente com projeções vascularizadas e ramificadas (Fig. 3c), com tricomas simples Pterolepis glomerata

5'. Hipanto externamente sem projeções vascularizadas e ramificadas, glabro ou com tricomas simples, estrelados ou dendríticos.

6. Estames com anteras de ápice subulado combinadas com conectivos com apêndices subulados (Fig. 2i) Microlepis oleifolia

6'. Estames com anteras de ápice subulado combinadas com conectivos com apêndices curtos, com ápice obtuso ou anteras de ápice truncado combinadas com conectivos com apêndices subulados (apenas em T. hospita) Tibouchina (tratado em Meyer et al. 2010). 


\section{Aciotis D.Don}

Ervas. Folhas planas. Flores 4-meras; hipanto glabro ou pubescente; estames 8 , ambos os ciclos presentes, conectivo ausente ou pouco conspícuo, inapendiculado, anteras com ápice obtuso; ovário com ápice glabro ou coroado por indumento.

As espécies de Aciotis apresentam inflorescências cimosas ou paniculadas, flores tetrâmeras, com pétalas agudas, e ovário na maioria das vezes bilocular, raro trilocular (FreireFierro 2002). O fruto é geralmente capsular, mas algumas espécies possuem frutos bacáceos e indeiscentes (Freire-Fierro 2002), e por isso podem ser confundidas com espécies de Leandra e Ossaea, ambas em Miconieae. O gênero possui 13 espécies que ocorrem desde o Sul do México e Caribe até o Sul do Brasil (Freire-Fierro 2002). Todas as espécies do gênero ocorrem no Brasil (Matsumoto \& Martins 2009), e estão presentes em quase todos os estados, à exceção da Região Sul, onde apenas A. paludosa ocorre no Paraná (Baumgratz 2010).

1.1 Aciotis paludosa (Mart. ex DC.) Triana, Trans. Linn. Soc. London 28(1): 51. $1871 . \quad$ Fig. 1a-f Ervas $14-50 \mathrm{~cm}$ alt. Folhas com pecíolo 5,5-31,7 mm compr.; lâmina 1,8-5,6 × 1,1-2,6 $\mathrm{cm}$, elíptica ou oval, base aguda ou obtusa, ápice agudo, margem crenulada; ambas as faces esparso a moderadamente setulosas; nervuras $3+2$ ou 5 , pares laterais confluentes. Inflorescências cimosas ou tirsóides terminais. Flores com hipanto esparsamente glanduloso-pubérulo; cálice persistente, lacínias com ápice agudo; pétalas lilases ou roxas; estames pouco desiguais, filetes glabros, conectivos ca. 0,2 $\mathrm{mm}$ compr., inapendiculados, anteras com ápice obtuso; ovário com ápice glabro; estilete glabro. Cápsula 3-3,8 $\times 2,8-3,4 \mathrm{~mm}$.

Material examinado: Guaraqueçaba, Rio Morato, 4.II.1971, fl. e fr., G. Hatschbach 26249 (MBM); 7.XII.1972, fl. e fr., G. Hatschbach 30948 (MBM).

Material adicional examinado: BAHIA: Nova Viçosa, Rio Pau Velho, 8.XI.1986, fl. e fr., G. Hatschbach \& J.M. Silva 50740 (MBM). MINAS GERAIS: São Gonçalo do Rio Abaixo, Estação Ambiental de Peti, 8.XII.2004. fl. e fr., R.M. Ferreira et al. 67 (UPCB). SÃO PAULO: Ubatuba, Morro do Corsário, 15.I.2006, fr., A.K.A. Santos et al. 698 (UPCB). ESPIRÍTO SANTO: Santa Teresa, Estação Biológica de Santa Lúcia, 20.XI.1985, fl. e fr., J.M. Vimercat 300 (UPCB).

Aciotis paludosa tem por característica marcante o indumento avermelhado que reveste os ramos e pecíolos. Poucas amostras foram verificadas até o momento no Paraná, todas procedentes do município de Guaraqueçaba, o que representa o extremo sul de distribuição da espécie e do gênero. Não é endêmica do Brasil, mas neste país ocorre nos Estados do Mato Grosso, Distrito Federal, Bahia, Espírito Santo, Rio de Janeiro, Minas Gerais, São Paulo e Paraná (Baumgratz 2010; Freire-Fierro 2002; Matsumoto \& Martins 2009). No Paraná foi coletada em locais de baixa altitude, onde a água permanece acumulada, em Floresta Ombrófila Densa. Apresenta flores e frutos entre os meses de dezembro e fevereiro.

\section{Acisanthera $\mathrm{P}$. Browne}

Ervas ou subarbustos. Folhas planas. Flores 4-5-meras; hipanto glabro ou pubescente; estames (4)-8-10, ambos os ciclos presentes, raro um dos ciclos imperfeito, conectivo prolongado abaixo das tecas, apêndices ventrais bilobados com ápice obtuso, anteras com ápice subulado ou truncado; ovário com ápice glabro.

Acisanthera assemelha-se a Tibouchina, especialmente das espécies de pequeno porte, pelos estames dispostos em dois ciclos dimórficos, anteras subuladas na maioria das espécies com poro apical-ventral, conectivos longamente prolongados (geralmente nos estames antesépalos), com apêndices ventrais bituberculados, diferindo, no entanto, pela ausência de tricomas no ápice do ovário. Acisanthera apresenta cerca de 20 espécies, que ocorrem desde o Sul do México e América Central até o Paraguai, Argentina e sul do Brasil (Guimarães 2009). No Brasil ocorrem aproximadamente 13 espécies, com ampla distribuição por todo o Brasil (Kriebel 2010).

2.1 Acisanthera variabilis (DC.) Triana, Trans. Linn. Soc. London 28(1): 34. $1871 . \quad$ Fig. 1g-k

Ervas ou subarbustos $20-40 \mathrm{~cm}$ alt. Folhas com pecíolo ausente ou muito curto, 1,2-4 mm compr.; lâmina 1,2-3,3 × 1,2-2,3 cm, oval, base obtusa ou subcordada, ápice agudo, acuminado ou obtuso, margem inteira ou crenulada; face adaxial glabra ou esparsa a moderadamente pubérula, com tricomas glandulares mesclados, face abaxial moderadamente glanduloso-pubérula; nervuras 3 , $3+2,5$ ou $5+2$, basais. Inflorescências tirsóides ou cimeiras paucifloras terminais. Flores 5-meras; hipanto moderadamente glanduloso-pubérulo; cálice persistente, lacínias com ápice subulado; 


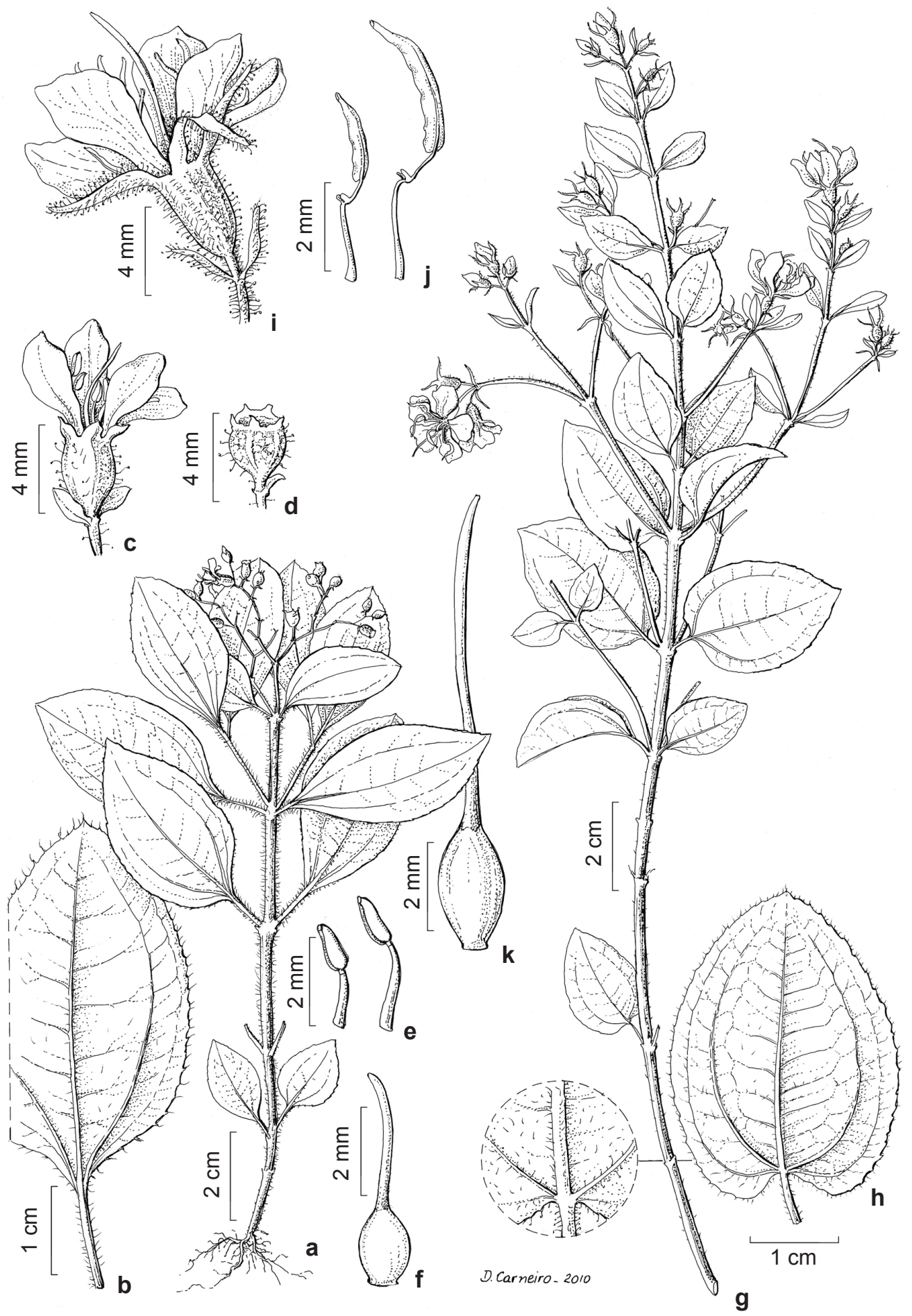

Figura 1 - a-f. Aciotis paludosa - a. hábito; b. folha (face abaxial); c. flor; d. fruto; e. estames; f. gineceu ( $G$. Hatschbach 26249). g-k. Acisanthera variabilis - g. hábito; h. folha (face abaxial) e detalhe do indumento; i. flor; j. estames; k. gineceu (R. Wasum 3441).

Figure 1 - a-f. Aciotis paludosa - a. habit; b. leaf (abaxial view); c. flower; d. fruit; e. stamens; f. gynoecium (G. Hatschbach 26249). g-k. Acisanthera variabilis - g. habit; h. leaf (abaxial view) and indument; i. flower; j. stamens; k. gynoecium (R. Wasum 3441$)$. 
pétalas róseas, roxas ou brancas; estames 10 , desiguais, filetes glabros, conectivos nos antesépalos longamente prolongados, 1,5-2,2 $\mathrm{mm}$ compr., nos antepétalos ca. 0,3 mm compr., apêndices ventrais bilobados com ápice obtuso, anteras com ápice subulado; estilete glabro. Cápsula 4,9-5,1 × 3,8-4 mm.

Material examinado: Altônia, Fazenda Pontal II, 12.XI.2002, fl. e fr., C. Kozera 1575 (MBM, UPCB). Balsa Nova, Ponte dos Arcos, 12.II.2008, fl. e fr., F.S. Meyer et al. 589 (UPCB). Bocaiúva do Sul, 5.XII.1978, fl. e fr., G. Hatschbach 41846 (MBM). Campina Grande do Sul, 8.XI.1985, fl., R. Kummrow \& S. Graham 2633 (MBM). Campo Largo, São Luiz do Purunã, 6.XI.2001, fl. e fr., R. Goldenberg et al. 539 (UPCB). Campo Mourão, Parque Estadual do Lago Azul, 3.II.2007, fl., A.R. Silva 279 (UPCB). Castro, Rio São João, 15.I.1965, fl., G. Hatschbach et al. 12125 (MBM). Curitiba, Parque Barigüi, 7.V.1996, fl., fr., V.A. Dittrich \& C. Kozera 112 (MBM). General Carneiro, Cabeceiras do Iratim, 10.II. 1966, fl. e fr., G. Hatschbach et al. 13684 (MBM, UPCB). Guarapuava, Chácara Raul Toledo, 4.II.2006, fl. e fr., J. Cordeiro 341 (UPCB). Guaratuba, Rio Tupitininga, 25.XI.1996, fl. e fr., J.H. Pedrosa-Macedo et al. (UPCB 31425). Imbituva, Rio Imbituva, 5.III.1982, fl. e fr., R. Kummrow 1861 (MBM). Ipiranga, Rio Capivari, 19.XII.1970, fl. e fr., G. Hatschbach 25836 (MBM). Jaguariaíva, Parque Estadual do Cerrado, 12.VII.2005, fl. e fr., E. Barbosa et al. 1059 (MBM). Lapa, Gruta do Monge, 18.I.2006, fl., R. Wasum \& L. Scur 3441 (UPCB). Marmeleiro, estrada Marmeleiro-Campo Erê, 21.II.1971, fl., G. Hatschbach 25414 (MBM). Palmeira, Recanto dos Papagaios, 26.XI.2003, fl. e fr., A.C. Cervi 8577 (UPCB). Pinhão, Rondinha, 24.II.1996, fl. e fr., G. Hatschbach \& S.R. Ziller 64499 (MBM). Piraquara, Campo próximo ao Rio Iraí, 22.XII.1992, fl. e fr., A. Bufrem \& S.R. Ziller 36 (MBM). Ponta Grossa, Rio Tibagi, 31.I.1999, fl. e fr., S.R. Ziller 1733 (MBM). Porto Amazonas, Fazenda São Luiz, 22.XI.1963, fl. e fr., G. Hatschbach 10876 (MBM). Quatro Barras, Rio Taquari, 21.I.1999, fl. e fr., J. Cordeiro et al. 1495 (MBM). Rio Negro, Campo do Tenente, 1.IV.1951, fl., G. Hatschbach 3193 (MBM). São Jerônimo da Serra, Rio do Tigre, 24.II.1957, fl. e fr., G. Hatschbach 3629 (MBM). São José dos Pinhais, Aeroporto Afonso Pena, 27.XI.2004, fl., A.C. Martins $\&$ R.B. Gonçalves 40 (UPCB). Tibagi, Parque Estadual do Guartelá, 27.X.2005, fl. e fr., R. Goldenberg \& F. Michelangeli 826 (UPCB). Tijucas do Sul, Ambrósios, 10.I.1992, fl. e fr., O.S. Ribas \& J. Cordeiro 392 (MBM). Tuneiras do Oeste, 26.II.2004, fl. e fr., M.G. Caxambu 371 (UPCB). Ventania, Fazenda Santa Inês, 7.XII.2004, fl. e fr., D.A. Estevan et al. 616 (UPCB).

Acisanthera variabilis é uma espécie altamente polimórfica. As coleções depositadas em herbários estavam segregadas em duas entidades distintas, A. variabilis e A. alsinaefolia (DC.)
Triana, cuja distinção seria baseada na forma da margem, indumento e consistência das folhas, tamanho da inflorescência e nível de dimorfismo entre os dois ciclos de estames (Wurdack 1962). Aparentemente estas características variam mesmo dentro de uma população e, por isso, optou-se por incluir todos os espécimes sob A. variabilis, espécie citada para o sul do Brasil (Kriebel 2010). Provavelmente, A. variabilis seja sinônimo de $A$. quadrata Pers., mas a delimitação das espécies deste complexo ainda carece de revisão. Acisanthera variabilis é endêmica do Brasil e ocorre no Piauí, Paraíba, Bahia, Mato Grosso, Goiás, Distrito Federal, Minas Gerais, Espírito Santo, Rio de Janeiro São Paulo, Paraná e Santa Catarina (Kriebel 2010). No Paraná ocorre em locais alterados por pastagens e monoculturas, em Floresta Ombrófila Densa e Floresta Ombrófila Mista, mas também em Estepe e Savana. Apresenta flores e frutos durante boa parte do ano, entre outubro e junho.

\section{Marcetia DC.}

Arbustos ou subarbustos, raro ervas. Folhas assoveladas. Flores 4-meras; hipanto piloso, tomentoso ou glabro, raro setoso; estames 8 , ambos os ciclos presentes, conectivo pouco conspícuo, apêndices ventrais bilobados com ápice obtuso, pouco conspícuos; ovário com ápice glabro.

Marcetia difere dos demais gêneros paranaenses de Melastomeae especialmente pelas folhas diminutas e assoveladas. Possui cerca de 29 espécies, todas endêmicas do Brasil, à exceção de M. taxifolia, que ocorre na Colômbia, Venezuela e Guianas (Wurdack et al. 1993).

3.1 Marcetia taxifolia (A.St.-Hil.) DC., Prodr. 3: 124. 1828.

Fig. 2a-f

Arbustos $0,3-1 \mathrm{~m}$ alt. Folhas com pecíolo ausente ou muito curto, ca. $0,1 \mathrm{~mm}$ compr.; lâmina $0,3-0,4 \times 0,1-0,2 \mathrm{~cm}$, sagitada ou lanceolada, assovelada, base cordada, ápice acuminado, margem revoluta; ambas as faces moderadamente pubérulas; nervuras 3, basais, pouco conspícuas. Flores solitárias, axilares ou dispostas nas regiões apicais dos ramos; hipanto moderado ou densamente glanduloso-pubérulo; cálice persistente, lacínias com ápice subulado; pétalas róseas ou roxas; estames pouco desiguais, filetes glabros, anteras com ápice subulado; estilete glabro. Cápsula 3,7-4,7 × 2,1-2,6 mm. 


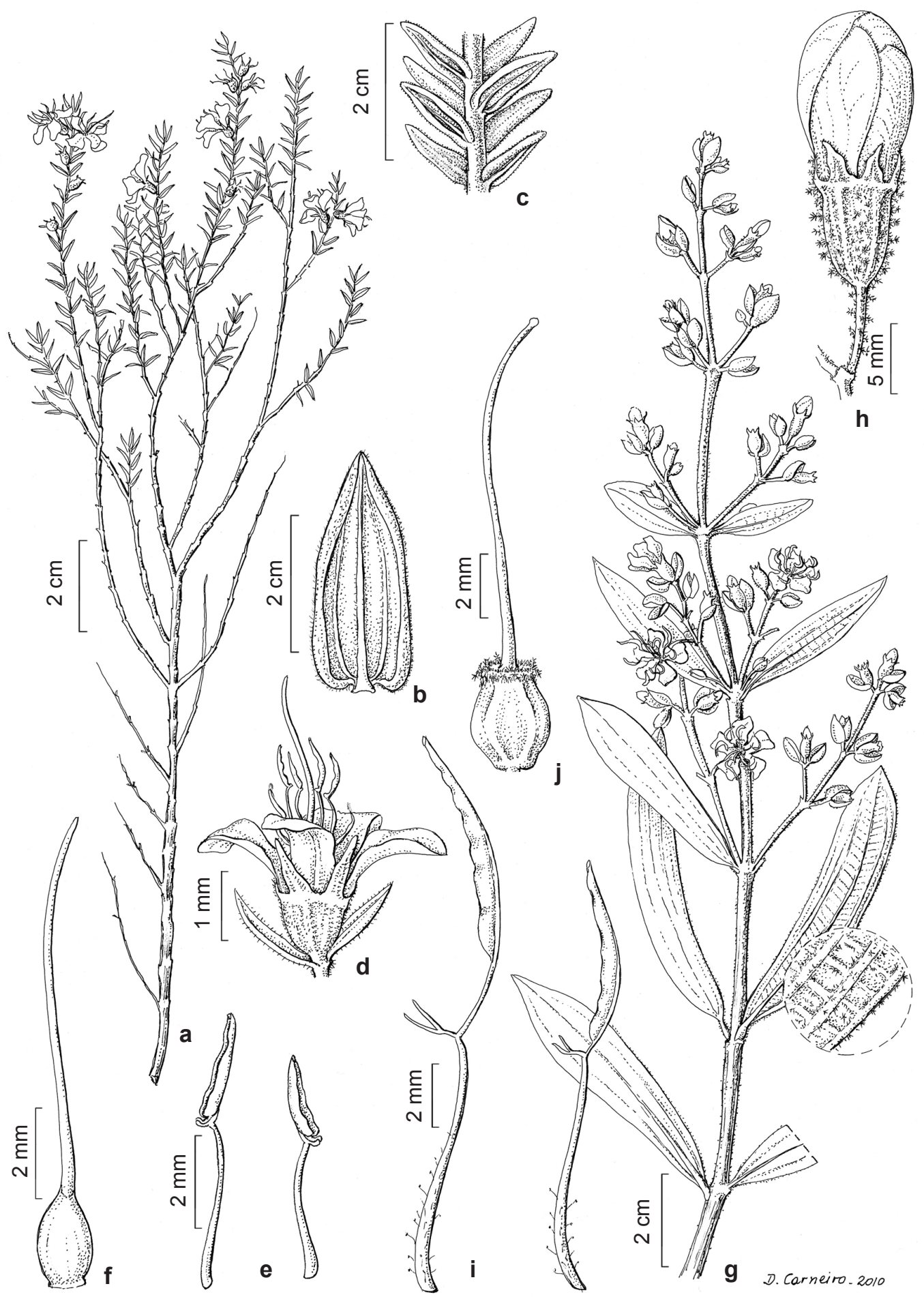

Figura 2 - a-f. Marcetia taxifolia - a. ramo; b. folha (face abaxial); c. disposição das folhas no ramo; d. flor; e. estames; f. gineceu (G. Hatschbach 27180). g-j. Microlepis oleifolia - g. ramo e detalhe do indumento sob a face abaxial da folha; h. botão; i. estames; j. gineceu (E. Barbosa 2061).

Figure 2 - a-f. Marcetia taxifolia - a. branch; b. leaf (abaxial view); c. leaves; d. flower; e. stamens; f. gynoecium (G. Hatschbach 27180). g-j. Microlepis oleifolia - g. branch and detail of the indument on the abaxial surface of the leaves; h. flower bud; i. stamens; j. gynoecium (E. Barbosa 2061). 
Material examinado: Sengés, Estrada Santo AntônioItararé, 8.X.1971, fl. e fr., G. Hatschbach 27180 (UPCB). Material adicional examinado: BAHIA: Maraú, Estrada de Itacaré a Maraú, 10.VII.2006, fl., S.C. Sant'Ana et al. 1274 (UPCB). ESPIRITO SANTO: São Roque do Canaã, Alto Misterioso, 25.VI.2007, fl. e fr., R.C. Britto et al. 186 (UPCB). MATO GROSSO: Rio das Contas, 7.IV.1992, fr., G. Hatschbach et al. 56788 (UPCB). MINAS GERAIS: Diamantina, Estribo Bandeirinha, 21.V.1989, fl., G. Hatschbach et al. 53017 (UPCB). PERNAMBUCO: Brejo da Madre Deus, Mata do Bituri, 18.VIII.1999, fl. e fr., A.G. da Silva \& L.M. Nascimento 131 (UPCB).

Marcetia taxifolia é a espécie de mais ampla distribuição geográfica do gênero, ocorrendo desde a Colômbia e Venezuela até o sul do Brasil (Martins 1989, Martins \& Bernardo 2010). No Paraná apenas uma coleta da espécie pôde ser verificada, originária de Estepe, em afloramentos de arenito no município de Sengés. Esta mesma coleta representa o registro mais ao sul de distribuição da espécie, acompanhando, por sua vez, os limites da vegetação de cerrado (Savana) no sul do Brasil. Coletada com flores e frutos em outubro.

\section{Microlepis (DC.) Miq.}

Arbustos. Folhas planas. Flores 5-meras; hipanto estrigoso-dendrítico e/ou estrigosoestrelado; estames 10, ambos os ciclos presentes, conectivo prolongado abaixo das tecas, apêndices ventrais subulados, anteras com ápice subulado; ovário com ápice tomentoso, com tricomas estrelados ou dendríticos.

Microlepis se assemelha muito a Tibouchina, diferindo pelos conectivos com apêndices subulados, combinados com anteras de ápice subulado, além da presença de tricomas estrelados no hipanto e lacínias (Romero 2000). Microlepis possui 3 espécies endêmicas do Brasil, que ocorrem nos estados da Região Sudeste (Romero 2010a), sendo este o primeiro registro do gênero para o Paraná e Região Sul do Brasil.

\subsection{Microlepis oleifolia (DC.) Triana, Trans. Linn.} Soc. Bot. 28(1): 36. 1871.

Fig. 2g-j

Arbustos 1-3 $\mathrm{m}$ alt. Folhas com pecíolo 4,2-6,7 mm compr.; lâmina 3,9-6 × 0,8-2 cm, lanceolada, base aguda ou obtusa, ápice agudo, margem inteira; ambas as faces densamente recobertas por tricomas estrelados ou dendríticos; nervuras $3+2$ ou 5 , pares laterais confluentes. Inflorescências tirsóides. Flores com cálice caduco, lacínias com ápice agudo; pétalas roxas ou lilases; estames desiguais, filetes esparsamente glanduloso-pubérulos, conectivos nos ante-sépalos ca. 3,4 mm compr., nos antepétalos ca. 0,3 mm compr., anteras com ápice subulado; estilete glabro ou esparsamente estrelado na base. Cápsula 4,5-5,7 × 3,5-3,9 $\mathrm{mm}$.

Material examinado: Castro, 2.III.1966, fl. e fr., $G$. Hatschbach \& H. Haas 13924 (MBM, UPCB). Imbituva, 11.IV.1965, fl. e fr., G. Hatschbach 12519 (MBM). Jaguariaíva, Rio Cilada, 18.II.1987, fl., G. Hatschbach \& A. Souza 50899 (MBM). Piraí do Sul, Vassoura, 26.II.2007, fl., E. Barbosa \& J.M. Silva 2061 (UPCB). Pitanga, 26.II.2004, fl., A.E. Bianek 202 (UPCB). Ponta Grossa, Vila Velha, 21.III.1973, fl. e fr., G. Hatschbach 31777 (MBM). São Jerônimo da Serra, Rio do Tigre, 24.II.1957, fl. e fr., G. Hatschbach 3627 (MBM).

Os exemplares provenientes do Paraná têm hipanto e lacínias revestidos por tricomas estrelados freqüentemente associados com tricomas dendríticos, ao invés de exclusivamente estrelados, como encontrado em materiais de outros estados (Cogniaux 1891; Romero 2000). Microlepis oleifolia é endêmica do Brasil, sendo previamente citada para os estados do Sudeste (Romero 2010a), sendo este o primeiro registro para o Estado do Paraná. Ocorre em Estepe, e apresenta flores e frutos entre os meses de fevereiro e abril.

\section{Pterolepis (DC.) Miq.}

Ervas ou subarbustos. Folhas planas. Flores (3-)4-5-meras; hipanto revestido por emergências vascularizadas e ramificadas, frequentemente associadas a tricomas simples, estames (6)-8-10, ambos os ciclos presentes, conectivo pouco conspícuo, apêndices ventrais bilobados com ápice obtuso; ovário com ápice coroado por indumento.

As espécies de Pterolepis são facilmente diferenciadas dos demais gêneros de Melastomeae pelo hipanto com projeções vascularizadas e ramificadas e tricomas simples. Tais projeções foram por engano designadas como tricomas "verticilados-penicilados" por Wurdack (1962). O gênero apresenta 14 espécies que ocorrem desde o Sul do México e Caribe até o Paraguai e Brasil (Renner 1994). Para o Brasil são citadas 13 espécies, com distribuição em diversos estados da costa leste brasileira (Romero 2010a).

\subsection{Pterolepis glomerata (Rottb.) Miq. Comm.} Phytogr. 2:78. 1840.

Fig. 3a-e

Ervas ou subarbustos $10-60 \mathrm{~cm}$ alt. Folhas com pecíolo 0,9-2,3 mm compr.; lâmina 1,4-1,9 
$\times 0,5-1 \mathrm{~cm}$, oval ou elíptica, base obtusa, ápice agudo, margem crenulada; ambas as faces moderadamente estrigosas, tricomas de base imersa no limbo na face adaxial; nervuras 3, basais. Inflorescências cimosas, glomerulares, terminais, raro flores solitárias. Flores 4-meras; cálice persistente, lacínias com ápice agudo; pétalas róseas ou brancas; estames 8 , desiguais, filetes glabros, conectivo nos ante-sépalos $0,5 \mathrm{~mm}$ compr., nos antepétalos $0,3 \mathrm{~mm}$ compr., anteras com ápice subulado; estilete glabro. Cápsula ca. $9,4 \times 3,6 \mathrm{~mm}$

Material examinado: Antonina, Ponta Feliz, 9.VIII.1973, fl. e fr., G. Hatschbach 32286 (MBM). Guaíra, Sete Quedas, 24.II.1982, fl. e fr., R. Kummrow \& J.G. Stutts 1801 (MBM). Guaraqueçaba, Itaqui, 16.V.2003, fl., E. Barbosa et al. 773 (MBM). Guaratuba, Rio Imbira, 27.VI.1971, fl. e fr., G. Hatschbach 26821 (MBM). Morretes, Estação IAPAR, 9.IV.1995, fr., I. Barbola (UPCB 29029). Paranaguá, Balneário Canoas, 2.IX.1980, fl. e fr., G. Hatschbach 43181 (MBM). Pontal do Paraná, Ipanema, 13.X.1994, fl. e fr., N.T. Kokubo 2 (UPCB).

Pterolepis glomerata assemelha-se às espécies de Tibouchina que possuem porte herbáceo e frutos com as lacínias persistentes, pertencentes às seções Diotanthera, Pseudopterolepis e Simplicicaulis. Delas difere, especialmente, pelo hipanto com projeções vascularizadas ramificadas e tricomas simples. Assemelha-se também à Acisanthera variabilis, que possui porte herbáceo e anteras com ápice subulado, diferindo pelo hipanto com projeções vascularizadas ramificadas e tricomas simples, e também pelo ovário com ápice coroado por indumento. É endêmica do Brasil, ocorrendo em Roraima, Pará, Maranhão, Piauí, Ceará, Rio Grande do Norte, Pernambuco, Bahia, Goiás, Minas Gerais, Rio de Janeiro, São Paulo, Paraná e Santa Catarina (Romero 2010b). No Paraná esta espécie está freqüentemente associada a áreas degradadas ou em regeneração em região de Floresta Ombrófila Densa de Terras Baixas (restinga), e também em Floresta Estacional Semidecidual (Renner 1994). Floresce e frutifica durante o ano todo.

\section{Siphanthera Pohl ex DC.}

Ervas ou subarbustos. Folhas planas. Flores 4-meras; hipanto glanduloso-piloso; estames 4-8, ciclo antepétalo rudimentar ou ausente, conectivo pouco conspícuo, apêndices ventrais bilobados com ápice obtuso; anteras com ápice rostrado ou truncado; ovário com ápice glabro.
As espécies de Siphanthera possuem porte reduzido e, muito provavelmente por esta razão, estão pouco representadas em herbários (Romero 1997). Difere dos demais gêneros de Melastomeae no Paraná pela presença de apenas 4 estames nas flores (ciclo antepétalo ausente). Siphanthera possui 15 espécies que ocorrem na Colômbia, Peru, Venezuela, Guianas, Brasil e Bolívia (Almeda \& Robinson 2011). No Brasil ocorrem 12 espécies, que se distribuem em Estepe, Savana e Floresta Ombrófila Densa nos estados de Roraima, Amapá, Acre, Rondônia, Amazonas, Pará, Tocantins, Bahia, Mato Grosso, Mato Grosso do Sul, Goiás, Minas Gerais, Rio de Janeiro e São Paulo (Almeda \& Robinson 2011; Romero 2010c), sendo este o primeiro registro para o Paraná e Região Sul do Brasil.

6.1 Siphanthera cordata Pohl ex DC., Prodr. 3: 121. 1828. Fig. 3f-1

Ervas $20-40 \mathrm{~cm}$ alt. Folhas com pecíolo ausente ou muito curto, ca. $1 \mathrm{~mm}$ compr.; lâmina ca. $4 \times 5 \mathrm{~mm}$, oval, base cordada, ápice agudo, margem crenulada; ambas as faces moderado ou densamente pubérulas; nervuras $3-5$, basais. Inflorecências cimosas, glomerulares, terminais ou axilares. Flores com hipanto esparsamente glanduloso-pubérulo; cálice persistente, lacínias com ápice agudo; pétalas róseas; estames 4 , ciclo antepétalo ausente, filetes glabros, conectivo pouco conspícuo, ca. $0,1 \mathrm{~mm}$ compr., anteras com ápice rostrado; estilete glabro. Cápsula ca. $4,7 \times 1,8 \mathrm{~mm}$.

Material examinado: Balsa Nova, Ponte dos Arcos, 8.IV.2006, fl., C. Kozera \& O.P. Kozera 3126 (MBM). Material adicional examinado: DISTRITO FEDERAL: Brasília, Cabeceira Comprida, 25.IV.1983, f1., J.H. Kirkbride Jr. 5258 (MBM). GOIÁS: Ipameri, Ponte Alta, 11.IV.1981, fl., G. Hatschbach 43805 (MBM). MATO GROSSO: Cuiabá, São José da Serra, 17.V.1973, fr., G. Hatschbach 32050 (MBM). MINAS GERAIS: Joaquim Felício, Serra do Cabral, 7.VI.2004, fl. e fr., G. Hatschbach et al. 77617 (MBM).

Siphanthera cordata possui apenas um registro para o Paraná, sendo anteriormente citada apenas para Mato Grosso, Goiás, Minas Gerais e São Paulo (Romero 2009b; Romero 2010c). Difere dos demais representantes de Melastomeae do Paraná pelas flores com apenas quatro estames e folhas diminutas, planas. No Paraná foi coletada em Estepe e, provavelmente, representa o limite sul da espécie. Floresce e frutifica no mês de abril. 


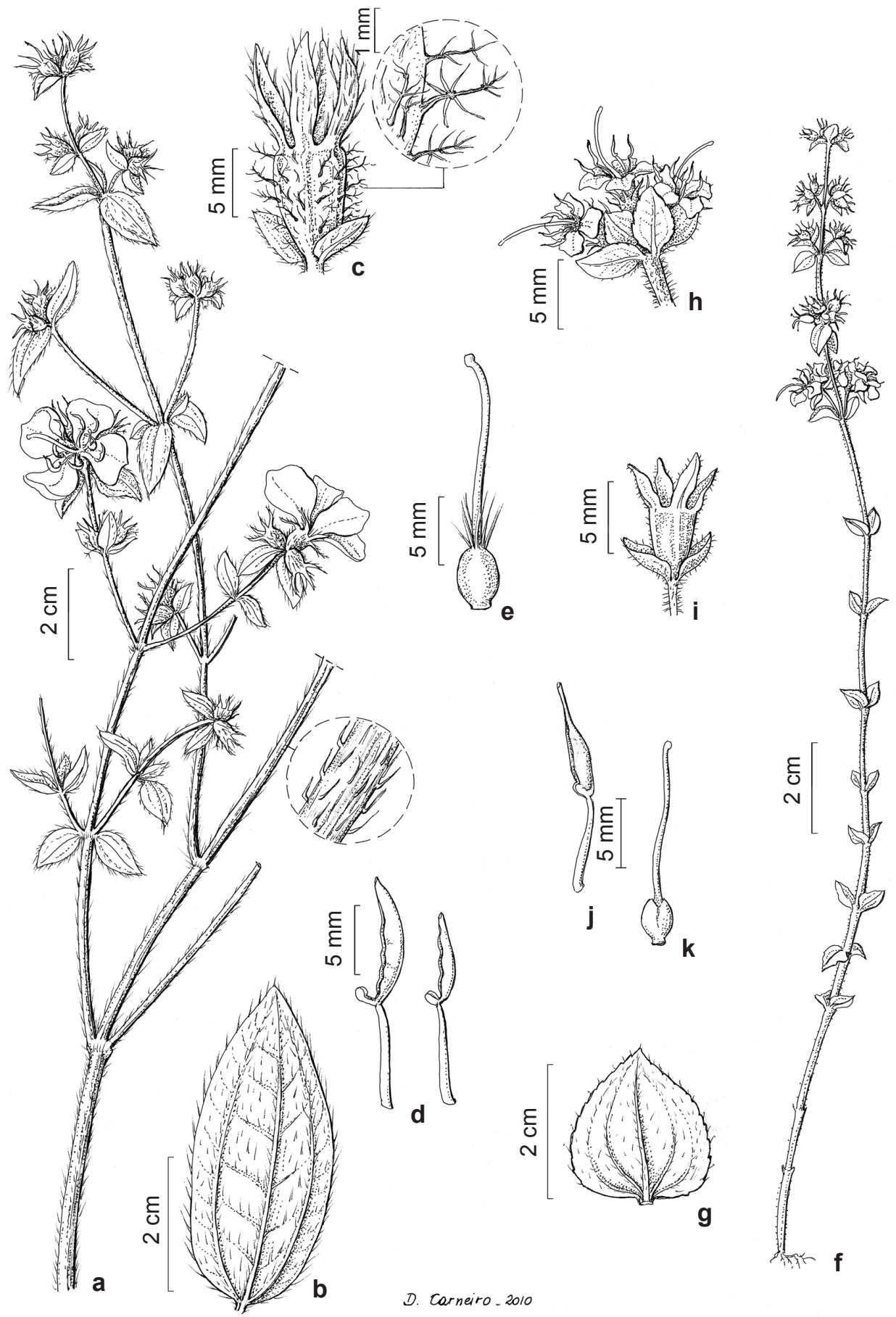

Figura 3 - a-e. Pterolepis glomerata - a. hábito e detalhe do indumento sob os ramos; b. folha (face abaxial); c. hipanto e detalhe das projeções vascularizadas recobertas por tricomas; d. estames; e. gineceu (A.L.S. Gatti 74). f-1. Siphanthera cordata - f. hábito; g. folha (face abaxial); h. inflorescência; i. fruto; j. estame; k. gineceu ( $C$. Kozera 3126).

Figure 3 - a-e. Pterolepis glomerata - a. habit and indument on young shots; b. leaf (abaxial view); c. hypanthium and the details of vascular projections covered with trichomes; d. stamens; e. gynoecium (A.L.S. Gatti 74). f-1. Siphanthera cordata - f. habit; g. leaf (abaxial view); h. inflorescence; i. fruit; j. stamen; k. gynoecium (C. Kozera 3126). 


\section{Agradecimentos}

Os autores são gratos aos curadores dos herbários citados, a Ricardo Kriebel pelas informações cedidas sobre o gênero Acisanthera, e a Diana Carneiro pela confecção das ilustrações.

\section{Referências}

Almeda, F. \& Robinson, O.R. 2011. Systematics and phylogeny of Siphanthera (Melastomataceae). Systematic Botany Monographs 93: 1-101.

Baumgratz, J.F.A. 2010. Aciotis. In: Forzza, R.C. et al.(eds.). Lista de espécies da flora do Brasil. Jardim Botânico do Rio de Janeiro. Disponível em $<$ http:// floradobrasil.jbrj.gov.br/2010/FB009392>. Acesso em 10 Dez 2010.

Clausing, G. \& Renner S.S. 2001. Molecular phylogenetics of Melastomataceae and Memecylaceae: implications for character evolution. American Journal of Botany 88: 486-498.

Cogniaux, A. 1883-1885. Melastomataceae. In: Martius, C.F.P. von; Eichler,A.W. \& Urban, I. Flora brasiliensis. Lipsae, Munchen. Vol.14(3). Pp. 206-480.

Cogniaux, A. 1891. Melastomataceae. In: De Candolle, A. \& De Candolle, C. (eds.). Monographiae phanerogamarum. Vol. 7. G. Masson, Paris. Pp 1-1256.

Freire-Fierro, A. 2002. Monograph of Aciotis (Melastomataceae). Systematic Botany Monographs 62: 1-99.

Goldenberg, R. 2004. O gênero Miconia (Melastomataceae) no estado do Paraná, Brasil. Acta Botanica Brasilica 18: 927-947.

Guimarães, P.J.F. 2009. Acisanthera P. Browne. In: Wanderley, M.G.L., Shepherd, G.J., Melhem, T.S.; Giulietti, A.M. \& Martins, S.E. (eds.). Flora fanerogâmica do Estado de São Paulo. Vol. 6. FAPESP, São Paulo. Pp 5-7.

Kriebel, R. 2010. Acisanthera. In: Forzza, R.C. et al.(eds.). Lista de espécies da flora do Brasil. Jardim Botânico do Rio de Janeiro. Disponível em < http:// floradobrasil.jbrj.gov.br/2010/FB009397>. Acesso em 10 Dez 2010.

Maack, R. 1968. Geografia física do estado do Paraná. BADEP/UFPR/IBTP, Curitiba. 350p.

Martins, A.B. 1989. Revisão taxonômica do gênero Marcetia DC - (Melastomatace0000000ae). Tese de Doutorado. Universidade Estadual de Campinas, Campinas. 234p.

Martins, A.B. 2009. Marcetia DC. In: Wanderley, M.G.L.; Shepherd, G.J.; Melhem, T.S.; Giulietti, A.M. \& Martins, S.E. Flora fanerogâmica do Estado de São Paulo. Vol. 6. FAPESP, São Paulo. Pp. 69-70.

Martins, A.B. \& Bernardo, K.F.R. 2010. Marcetia. In: Forzza, R.C. et al.(eds.). Lista de espécies da flora do Brasil. Jardim Botânico do Rio de Janeiro. Disponível em $<$ http://floradobrasil.jbrj. gov.br/2010/FB009648>. Acesso em 10 Dez 2010.

Matsumoto, K. \& Martins, A.B. 2009. Aciotis D. Don. In: Wanderley, M.G.L.; Shepherd, G.J.; Melhem, T.S.; Giulietti, A.M. \& Martins, S.E. (eds.). Flora fanerogâmica do Estado de São Paulo. Vol. 6. FAPESP, São Paulo. Pp 4.

Meyer, F.S.; Guimarães, P.J.F. \& Goldenberg, R. 2010. Tibouchina (Melastomataceae) do estado do Paraná, Brasil. Rodriguésia 61: 615-638.

Penneys, D.S.; Michelangeli, F.A.; Judd, W.S. \& Almeda, F. 2010. Henrietteeae (Melastomataceae): a new tropical berry-fruited tribe. Systematic Botany 35: 783-800.

Renner, S.S. 1993. Phylogeny and classification of the Melastomataceae and Memecylaceae. Nordic Journal of Botany 13: 519-540.

Renner, S.S. 1994. A revision of Pterolepis (Melastomataceae: Melastomeae). Nordic Journal of Botany 14: 73-104.

Romero, R. 1997. O gênero Siphanthera Pohl. ex DC. (Melastomataceae) no estado de Minas Gerais. Revista Brasileira de Botânica 20: 175-183.

Romero, R. 2000. A família Melastomataceae no Parque Nacional da Serra da Canastra, Minas Gerais, Brasil. Tese de Doutorado. Universidade Estadual de Campinas. 326p.

Romero, R. 2009a. Microlepis (DC.) Miq. In: Wanderley, M.G.L.; Shepherd, G.J.; Melhem, T.S.; Giulietti, A.M. \& Martins, S.E. (eds.). Flora fanerogâmica do estado de São Paulo. Vol. 6. FAPESP, São Paulo. Pp 103-104.

Romero, R. 2009b. Siphanthera Pohl ex DC. In: Wanderley, M.G.L.; Shepherd, G.J.; Melhem, T.S.; Giulietti, A.M. \& Martins, S.E. (eds.). Flora fanerogâmica do estado de São Paulo. Vol. 6. FAPESP, São Paulo. Pp 126-127.

Romero, R. 2010a. Microlepis. In: Forzza, R.C. et al. (eds.). Lista de espécies da flora do Brasil. Jardim Botânico do Rio de Janeiro. Disponível em <http:// floradobrasil.jbrj.gov.br/2010/FB009781>. Acesso em 10 Dez 2010.

Romero, R. 2010b. Pterolepis. In: Forzza, R.C. et al. (eds.). Lista de espécies da flora do Brasil. Jardim Botânico do Rio de Janeiro. Disponível em < http:// floradobrasil.jbrj.gov.br/2010/FB009857>. Acesso em 10 Dez 2010.

Romero, R. 2010c. Siphanthera. In: Forzza, R.C. et al. (eds.). Lista de espécies da flora do Brasil. Jardim Botânico do Rio de Janeiro. Disponível em $<$ http:// floradobrasil.jbrj.gov.br/2010/FB009870>. Acesso em 10 Dez 2010.

Thiers, B. (continuously updated). Index Herbariorum: a global directory of public herbaria and associated staff. New York Botanical Garden's Virtual 
Herbarium. Disponível em $<$ http://sweetgum.nybg. org/ih/>. Acesso em 13 Ago 2011.

Wurdack, J.J.; Morley, T. \& Renner, S. 1993. Melastomataceae. In: Görts von Rijn, A.R.A. (ed.). Flora of the Guianas. V. 99. Koeltz Scientific Books. Pp 1-425

Wurdack, J.J. 1962. Melastomataceae of Santa Catarina. Sellowia 14: 109-217.

Lista de exsicatas

Athayde, S.F.: 42(5), Barbola, I.: s.n. (UPCB 29029)(5). Barbosa, E.: 773(5), 1059(2), 2061(4). Barreto, M.: 6865(4). Bianek, A.E.: 202(4). Britto, R.C.: 186(3). Budziak, C.: 17(2). Bufrem, A.: 36(2). Buttura, E.: 114(5). Carrião, D.J.S.: 53(2). Caxambu, M.G.: 371(2), 1358(2). Cervi, A.C.: 3545 (2), 8577 (2). Cordeiro, J.: 341(2), 1495(2). Dittrich, V.A.: 112(2). Estevan, D.A.: 616(2). Ferreira, R.M.: 67(1). Filho, H.M.: 256(2). Gatti, A.L.S.: 74(5). Gatti, G.: 638(5). Goldenberg, R.: 494(2), 539(2), 826(2). Hatschbach, G.: 3193(2), 3627(4), 3629(2), 5112(2), 8502(2), 8873(2), 10142(2), 10876(2), 11336(5), 11579(5), 12125(2), 12519(4), 13675(2), 13684(2), 13924(4), 18317(2), 18803(4), 19091(5), 19432(5), 24887(5), 25414(2), 25836(2), 26249 (1), 26821(5), 27180(3), 30948(1), 31777(4), 32050(6), 32286(5), 39825(5), 39934(4), 40232(2), 41846(2), 43181(5), 43805(6), 50740(1), 50899(4), 53017(3), 54063(4), 56788(3), 58032(1), 64499(2), 69043(4), 77617(6). Imaguire, N.: 2334(2), 2713(2), 3192(2). Kirkbride Jr., J.H.: 5258(6). Kokubo, N.I.: 2(5). Kozera, C.: 1575(2), 2213(2), 2544(2), 2917(2), 3126(6). Krapovickas, A.: 39732(2). Krieger, P.L.: 7739(2). Kummrow, R.: 226(2), 450(4), 1216(2), 1801(5), 1861(2), 2121(2), 2180(2), 2205(2), 2633 (2). Kuniyoshi, Y.S.: 5020(5). Landrum, L.R.: 2522(2). Lange, R.: s.n. (UPCB 2501)(2). Lima, R.X.: 17(5), 52(5). Lindeman, J.C.: 32(2), 305(2), 871(2). Maia, D. C.: s.n. (UPCB 50232)(2). Martins, A.C.: 40(2). Meyer, F.S.: 589(2). Moreira, H.: 407(5). Oliveira, J.E.: 75(6). Oliveira, P.I.:834(2). Pedrosa-Macedo, J.H.: s.n. (UPCB 31425) (2). Pereira, E.: 8283(2). Ribas, O.S.: 383(2), 392(2), 4524(2). Sant'Ana, S.C.: 1274(3). Santos, A.K.A.: 698(1). Santos, E.P.: 645(2). Silva, A.G.: 131(3). Silva, A.R.: 279(2). Silva, I.: s.n. (UPCB 43561)(5). Souza, L.R.M.: 175(5). Souza, V.C.: 3232(4), 22433(6). Tessmann, G.: 3722(2), s.n. (MBM 271029)(2), s.n. (MBM 757910)(2). Uhlmann, A.: s.n. (UPCB 34062)(2).Vieira, M.E.M.: 24(2), 35(2). Vimercat, J.M.: 300(1). Von Lisingen, L.:126(2). Wasum, R.: 3441(2). Ziller, S.R.: 895(5), 1679(2), 1733(2), 1958(2). 